Volume: 11 Issue: 2 Year: 2014

\title{
Examining experiential qualities on the stage: A study on leisure experience of Salsa dancing
}

\author{
Müge Akyıldız ${ }^{1}$ \\ Süleyman Munusturlar ${ }^{2}$
}

\begin{abstract}
With the increased popularity of social dances as a leisure activity in Turkey, there is a need to explore different aspects of experience associated with the participation in social dance events. In this sense, the purpose of this study was to examine leisure experiences of the "dancers" on the stage and to discuss the most important experiential qualities of salsa events from participants' perspectives. Focus groups were chosen as the most appropriate data collection method in this study. Purposive sampling procedure was adopted in this research to select potential respondents. Participants who attended Sunday Dance Nights $(n=6), 1^{\text {st }}$ Eskisehir Dance Festival $(n=10)$, and Salsa workshops before the dance parties $(n=8)$ in the city of Eskisehir were chosen as a sample. For labeling the emerged themes, existing leisure experience literature was frequently consulted. A total of five preliminary themes based on Schmitt's experiential modules -sense experience, emotional experience, think experience, act experience and relational experience- were examined in the context of experiential qualities of Salsa dancing. According to results, it was found that the sense experience is the most important dimension among the other experiences because engaging all five senses on the stage is very important for active involvement to the dance events.
\end{abstract}

Keywords: Leisure; Leisure experience; Dancing; Salsa; Events

\section{Introduction}

The experiences of leisure activities have become appreciated over the past few years. Dancing, which is a common leisure activity in many communities (Lagomarcino et al., 1984), provides different kinds of leisure experiences such as social interaction, understanding of one's own culture, and opportunity for the new experience. Unlike other activities, dancing allows participants to concentrate on each other rather than play to an audience or strive to meet regimented skill specifications. Dancing may decrease isolation, loneliness and boredom, increase tactile support,

\footnotetext{
${ }^{1}$ Assist. Prof. Dr., Anadolu University, Sport Sciences Faculty, Recreation Department, mugeakyildiz@anadolu.edu.tr

2 Res. Assist., Anadolu University, Sport Sciences Faculty, Recreation Department, suleymanmunusturlar@anadolu.edu.tr
} 
Akylldı, M., Munusturlar, S. (2014). Examining experiential qualities on the stage: A study on leisure experience of Salsa dancing. International Journal of Human Sciences, 11(2), 625-635. doi: 10.14687/ijhs.v11i2.2999

cooperation and enjoyment, and it also gives participants something to do with their hands, feet, and body if communicating on a purely verbal level is awkward (Crenan, 1993).

In some studies (Bond and Stinson, 2007; Wearing et al., 1994), examining people's experiences in dancing, it was found that dancing could be an open celebration of sensuality, and engagement and enjoyment are the two of the defining experience of dance education. Beside enjoyment and engagement dancing can also provide some other leisure experiences such as creativity, selfexpression, relaxation, escape, recognition and social interaction. However, different types of dance can lead to different experiences and so different types of social interaction. For instance, line and folk dances allow for simultaneous interaction among the group. Mixers allow for short acquaintances with everyone participating in the dance. Square dances provide interaction for a small group of friends. Social dances allow a couple to interact apart from the group, although the steps from the social dances can be performed in line formation without the need for separating into couples (Crenan, 1993). Therefore, leisure experience may not be the same, as the nature of the social interactions with others in the leisure settings are believed to vary (Lee, 1999). From this point of view, it can be suggested that all kinds of dance forms can deliver different experiences to participants and experiences provided by the specific type of dance can vary across the nature of the dance (Lagomarcino et al., 1984).

In this sense, the presents study aims to examine the experiential qualities provided by Salsa - as a specific type of dance- which is arguably one of the most popular social dances in Turkey. With its burst of popularity in Turkey, the question has emerged why some people "get hooked" on salsa dancing in their leisure time. Therefore, the purpose of this study was to examine what kind of special experiences and unforgettable memories were provided at Salsa events held in EskisehirTurkey in 2013.

\section{Salsa}

Salsa dancing covers a wide variety of styles and music (Zimmerer, 2005). It has grown significantly over the last ten years from its roots in the Caribbean (mainly Puerto Rico and Cuba) and initial transfer to New York and Los Angeles to a phenomenon sweeping the world (Hamilton and Hewer, 2009). The dance itself maybe a spot dance, that is danced in one place or spot, or it may be danced as a travelling dance, moving about the floor to the line of dance. As one would imagine, with such a variety, there is no easy way to trace the roots of the dance. There is a large element of the Rumba, and some people say the Salsa evolved from the Mambo (Zimmerer, 2005).

Salsa dancing is a kind of shared experience that links individuals together resulting in a relaxed, friendly and comfortable atmosphere and it offers the opportunity for a union between the outer 
Akyıldı, M., Munusturlar, S. (2014). Examining experiential qualities on the stage: A study on leisure experience of Salsa dancing. International Journal of Human Sciences, 11(2), 625-635. doi: 10.14687/ijhs.v11i2.2999

representational body and the subjective experiential body. The experiential consumption of salsa provides meaning in life and offers enjoyment and ecstasy through connection. Therefore salsa dancing can result in total absorption as the dance floor becomes a beautiful place of euphoria (Hamilton and Hewer, 2009).

\section{Methods}

As a qualitative technique, focus groups allow for "rather than providing quantifiable responses to a specific question obtained from a large sampling of the population, focus group participants provide a flow of input and interaction related to topic or group of topics that the group is centered around" (Edmunds, 1999: 2). Focus groups provide creating a permissive environment, which encourages participants to share perceptions and points of views, without pressuring participants to vote or to reach consensus (Krueger and Casey, 2000).

In this study, it was hypothesized that leisure experiences would emerge as a result of performing Salsa on the stage, thus in order to assess the experiential qualities gained through Salsa dancing, focus group was chosen as the most appropriate data collection method in this study. Clark and Holmes (2007) indicated that focus groups are conducting with a purposive sampling method. Researchers attempt to choose the best sample group that believed to best represent the universe of the study (cited in Argan et al., 2009). Therefore, in constructing the focus groups, respondents were selected on the basis of being representative of the population. Purposive sampling procedure was adopted in this research to select potential respondents. They were chosen among the participants who attended different salsa events in the city of Eskisehir.

In order to select the respondents two basic criteria were used; a) participants who were known as more experienced in terms of involvement to the Salsa dancing, b) participants who have participated in different salsa events held in Eskisehir, because participants attended different dance events have different views and experiences were believed that they would generate an extensive data.

Despite the various views in the focus group literature on how many focus groups would be sufficient, the common view is when focus groups start to repeat themselves and come up with the same findings that indicates a cut-off point and is an ideal number for focus groups. The researcher usually compares and contrasts data from at least three focus groups (Krueger and Casey, 2000). In this research, three focus groups (session times are 59, 67 and 73 minutes respectively) were conducted including (1) participants of the Sunday Dance Nights $(n=6),(2)$ participants of the $1^{\text {st }}$ Eskisehir Dance Festival ( $\mathrm{n}=10$ ), and (3) participants of the Salsa workshops before the dance parties $(n=8)$. First focus group was held at the private dance school on $6^{\text {th }}$ of May, 2013 one week 
Akylldı, M., Munusturlar, S. (2014). Examining experiential qualities on the stage: A study on leisure experience of Salsa dancing. International Journal of Human Sciences, 11(2), 625-635. doi: 10.14687/ijhs.v11i2.2999

before the $1^{\text {st }}$ Eskisehir Salsa Festival (11 ${ }^{\text {st }}$ of May, 2013). Second and third focus groups were conducted on $18^{\text {th }}$ of May, 2013 after the festival.

The sample profile indicates that the gender of respondents was dominated by female participants $(66 \%)$. As for the ages, the ratio of participants who fall in 19-25 age brackets are $75 \%$, all of whom are student. Education status of the respondents consisted of bachelor degree (83\%) and postgraduate degree $(17 \%)$. All the participants are single. Lastly, the respondents were comprised of students (83\%), public officials $(12.5 \%)$, and the managers $(4 \%)$.

Focus group key questions were developed consistent with the previous researches into leisure experience (Borrie and Roggenbuck, 2001; Chao, 2003; Cotte, 1998; Gentile et al., 2007; Kao et al., 2008; Manfredo and Driver, 1996; Tsaur et al., 2006) (see Table 1).

\section{Table 1. Focus Group Key Questions}

1. How do you think the atmosphere should be organized in salsa events?

2. How do you feel while you are participating in salsa events?

3. How do you think the salsa events should be organized in order to lead creative thinking?

4. How do you think the salsa events should be organized in order to reinforce learning?

5. How do you think is your lifestyle overlap with salsa dancing?

In each focus group, researchers fulfilled the moderator role and recorded the findings. All the focus group interviews were audiotape recorded. Following the focus groups, written records were thoroughly investigated words by words and themes were determined based on the findings.

\section{Results}

For labeling the emerged themes, existing leisure experience literature was frequently consulted. A total of five preliminary themes based on Schmitt's experiential modules -sense experience, emotional experience, think experience, act experience and relational experience- were examined in the context of experiential qualities of Salsa dancing.

\section{Sense Experience}

Schmitt (1999) suggests that the sense experience appeals to the senses of the leisure participants with the objective of creating sensory experiences, through sight, sound, touch, smell and taste. Sense experience may be used to motivate participants and to add value (Tsaur et al., 2006) to the leisure experience so as to arouse aesthetical pleasure, excitement, satisfaction and sense of beauty of the participants (Gentile et al., 2007).

One of the key principles of sense experience is multisensory experience, because engaging all five senses on the stage is very important. Participants pointed out that for an entertaining experience, dance events should be organized for engaging all five senses because the more sensory experience, 
Akyldız, M., Munusturlar, S. (2014). Examining experiential qualities on the stage: A study on leisure experience of Salsa dancing. International Journal of Human Sciences, 11(2), 625-635. doi: 10.14687/ijhs.v11i2.2999

the more memorable it will be. One of the participants, Tugce, defined the sensory characteristics of the atmosphere which triggers all five senses as "well-organized with lighting, musicality, table set up, sound level and every other details" and she added "all features of the stage and musicality were perfect but the music was repetitive, DJ should refresh the repertoire periodically. Because we have almost memorized all the lyrics although they are Spanish... so different songs should be played?'

The other participants agreed that the event managers should provide music repertoire with different tempo and they added "we need to hear different songs, and then we will fly with different rhythm and tempo on the stage" because dancers are driven by what they hear. Seda defined dance experience as "it is all about what we hear, because I am always waiting patiently for the music which fill me with energy, and then can't wait to dance, so in that moment of pure joy, I feel like I am a bird or I am flying like a butterfly."

It is further indicated that event managers of the dance events should develop more aesthetical properties such as colorful lighting, table set up, stage characteristics. A female participant, Pelin suggested "the light is very important, because if it is so light, I feel like everybody is watching me and If it is too dark, I can't see my partner. So I think the atmosphere was so sensorial, so colorful. I was like I am a real dancer and performing on the stage alone! It was really good experience dancing under the purple light."

Another female participant, Sukriye emphasized the importance of the table set up to feel absorption and she suggested that "the table set up should be closer to the stage... Because I am coming dance nights with full of energy, but if the table is far away from the stage it is getting more difficult to involve to the event. I cannot see what is happening on the stage... but the worst thing to stand back is nobody offers dancing, so my energy is getting decreased."

\section{Emotional Experience}

To seek pleasure, to avoid pain, or more generally to avoid feeling bad is one of the core principles of life. Feel experience appeals participants' inner feelings and emotions with the objective of creating affective experiences that ran from mildly positive moods linked to a brand strong emotions of joy and pride (Schmitt, 1999).

As for the dance experience, there are always interactions and contacts because of the nature and social environment of dancing. Therefore it triggers emotions and inner feelings. In the focus groups, participants were asked to how they feel during or after dancing. They indicated that salsa dancing is a way of expressing their feelings, so they feel a sense of freedom, happiness, excitement, relaxation, enjoyment while they are dancing. Pelin said that "I am participating dance events just for fun, because I wouldn't be a professional dancer... sometimes I am so tired but nevertheless I am dancing until midnight losing the track of time. After the long night at the dance events, for example, waking up early is awful but it 
Akylldı, M., Munusturlar, S. (2014). Examining experiential qualities on the stage: A study on leisure experience of Salsa dancing. International Journal of Human Sciences, 11(2), 625-635. doi: 10.14687/ijhs.v11i2.2999

absolutely worth to be tired, because I feel myself happy and dynamic, it is really rewarding” and she further told that "excitement is the most important emotional experience in the dance events, for sure."

A participant named Seda said 'T feel like I can express myself through dancing. I feel freedom, it is not like doing workout because I feel as if I was flying, I feel free and it's coming from inside of me... There is a significant difference between my first dance experience on the stage and now. They are poles apart! So I am really happy to dance and to hear compliments about it."

While dancing with the dance teachers, Tugce explained her feelings as "they like dancing fastly and when they are moving fast and sharply, I feel very nervous if I can do or not... and sometimes they are leading me to do new figures, I feel so excited to learn but I can't. They are trying more than once. I try, try, try and eventually I can do. So it gives me self-confident. I feel like wooown I am dancing now." This would indicate that emotions can vary according to whom they are dancing with. A male participants, Ahmet told that "if I dance with the woman who is better than me, I feel very relaxed, because she knows everything and I know that she doesn't complain about my dance level, she teaches me new things and warns me when I do some mistakes. But if I dance any girl who has just started to learn salsa for example, she is not shining on the stage, not seem happy... So I prefer dancing with the professionals to have fun."

Apart from freedom, happiness, excitement, relaxation and enjoyment experiences, participants were asked about "love" on the stage. Gozde, a female participant, stressed that "I always dance passionately and I love salsa dancing... but love with somebody? No... I didn't fall in love but it can be some other time, why not, must be so romantic. I think salsa means love or passion in itself."

\section{Think Experience}

Engaging participants in using their creativity or in situations of problem solving (Gentile et al., 2007) constitute a form of experience so called think experience. Schmitt (1999) claims that think experience appeals to the intellect with the objective of creating cognitive, problem-solving experiences that engage participants creatively. Think experience appeals to target participants' convergent and divergent thinking through surprise, intrigue and provocation (Tsaur et al., 2006).

As for the think experience provided by Salsa events, participants claim that if the stimuli such as music and atmosphere lead to think, it will be easy to think creatively. Ozlem, one of the female participants, suggested "dancing on the stage is not like dancing in a regular dance class. Because in the class we are just learning the steps and stuck in the rules of the steps, there is no time to think creatively. I am always focusing on the steps without creating my own style! But in the dance nights for example, of course we are dancing without rules. We are just catching the rhythm and having fun... So it is much time for example to move free, to create my own style, to add new steps between the poses! Then I say to myself; Yes! This is me dancing on the stage! I find myself and I create something new so I create some Salsa shine steps fitting my body and myself." 
Akylldı, M., Munusturlar, S. (2014). Examining experiential qualities on the stage: A study on leisure experience of Salsa dancing. International Journal of Human Sciences, 11(2), 625-635. doi: 10.14687/ijhs.v11i2.2999

Participants were also asked to elaborate about their experiences on creativity or in situations of problem solving. Participants were indicated anonymously that creativity, if played upbeat music which makes them feel energetic, would certainly urge them to engage and inspire more. They all agreed that upbeat or high-octane salsa sounds urge them to think creatively. A student named Seda told that "Any Salsa song with fast tempo or upbeat music that I familiar with, inspires me to move, gives me more energy, so it is coming inside from me to think creatively and I am creating new styles like holding my hand, changing my leg position, doing hip action and adding extra movements. But if it is the bad music playing, it is even difficult to dance rather than to create new things!" Ersin added approvingly "dance is a connection between body and mind, so you should think while dancing, therefore you have to be engaged in what you are doing. In this sense, I think music is the most important stimuli for thinking creatively." Another girl named Hazal indicated that a different song rather than a familiar one makes the stage more enthusiastic, and she added "upbeat pulse of the music inspires movement in my entire body. The only thing to urge me to dance is of course music itself. Creativity requires the music, you know, rhythm should call you! I have always felt that it is and it will be strong enthusiasm that will set the stage for creativity. Then you can't help but move, can't resist the urge to dance, because creativity happens improvisationally when you hear the calling song."

To establish the ground for creativity and to solve problems, Tugce told "to promote creative thinking, event managers need to use their intellectual capabilities. In the dance nights for example I haven't found any situations or opportunities to come up with a new idea, because I always see the same people, same organization, same music, same place...so what to do? I think managers should create new ideas and, new concepts for the salsa nights. They can arrange some workshops by the famous dancers or they can perform artistic shine steps, shows etc. This would contribute to our style, because it is really good opportunity to see some other dancers' style and to have an idea about other styles of salsa, then it mustn't be too difficult to create things."

\section{Act Experience}

Act experiences are related with the physical body, long-term patterns of behavior and lifestyles as well as experiences occurring as a result of interacting with other people (Li, 2008). Actually, the main aim of the Salsa events for an act experience should be to promote attitude change and to reinforce learning through hands-on experience involving dancing on the stage and actively participation rather than just talking about salsa or following the steps. Therefore, participants were asked to elaborate about the effects and the importance of Salsa events on learning attitude and changing behavior. Ozlem told "when I dance with the professional dancers in the Festival for example, I can practice what I've learnt in the courses, so changing attitudes towards learning inevitably occurs. I think that events such as workshops and festivals are really great tool for reinforcing learning and providing challenge. Because the more we practice the better we learn. Especially, when I watch the performances and interact with the people, it will be easier 
Akyldız, M., Munusturlar, S. (2014). Examining experiential qualities on the stage: A study on leisure experience of Salsa dancing. International Journal of Human Sciences, 11(2), 625-635. doi: 10.14687/ijhs.v11i2.2999

to try what I learnt, and then it goes permanent learning." Pelin claimed that "at the salsa classes we are learning steps theoretically, we are just trying to follow the steps, but dance nights are not like that, performing on the stage is like making experiment in the laboratory so when we are dancing at the big event "1st Eskisebir Salsa Festival" for example, it means that wownw I am so ready to dance, I pumped for dancing to do some practice on the stage! Therefore act experience happens on the stage and I think it is applied learning."

Sukriye indicated that Salsa events could bring a tremendous motivation to a learning environment. She said that "focusing on steps during the workshops is sometimes getting difficult, however, as for the salsa nights and festivals, we are going there just for fun, so it is easy to focus on dancing, to remember the moves and to show yourselves on the stage... at last we are somehow motivated to dance! Enjoyment is the first requirement for learning. I believe that I am learning much more when I am actively involved in the events."

\section{Relational Experience}

The last experiential quality is relational experience, which contains aspects of sense, feel, think and act experience. However, relational experience expands beyond the individual's personal, private feelings, thus relating the individual to something outside his/her private state (Tsaur et al., 2006). Salsa events actually relate the participants to a broader social system, participants see dancing as a part of their identity and inevitably they are formed with strong bonds with dancing in their regular life. Therefore, participants indicated that relational experience at Salsa events is to relate their lifestyle with dancing and to promote dancing as a way of life.

They were asked to express their thoughts on the relationship between their lifestyle and dancing. Participants claim that dancing is the way of expressing themselves and it is a way of life. For example, Arinc said that "I believe that they are able to promote salsa dancing as a way of life... because whenever I hear salsa music, I wanna dance even if I am staying at the coffee shop or at my office for example. So anything can bring salsa to my mind. So, it means that dancing became as a way of life for me."

Participants also indicated that they miss dancing, their dance partners and friends, and they said that dancing makes life for them so meaningful. Hazal said "at holidays, I know that all dance events are cancelled. For example in the summer or in the Ramadan month, I was so bored and I wanted to dance. I thought that my only leisure time pursuit is going to dance events and dancing. Without dancing I felt myself bored and unsocial. Dance events bring people together, and gain them social identity. It is really good chance to be together with the people who can speak the same language; I mean dancing is a kind of body language. Therefore I think that dancing is wonderful way of expressing myself and I can't do without dancing so it is a way of life!" 
Akylldı, M., Munusturlar, S. (2014). Examining experiential qualities on the stage: A study on leisure experience of Salsa dancing. International Journal of Human Sciences, 11(2), 625-635. doi: 10.14687/ijhs.v11i2.2999

\section{Discussion and Conclusion}

This qualitative study examined the experiential qualities and experiences of the Salsa events held in Eskisehir. In this study it was aimed to find any kind of evidence about the nature and meaning of people's experiences in salsa dance. The most important experiential qualities of the salsa events from leisure participants' perspectives were examined; sense experience, emotional experience, think experience, act experience and relational experience.

Participants indicated that the sense experience is the most important dimension among the other experiences for their active involvement to the dance events. Because table set up, stage, lighting, musicality, volume, music repertoire and also the body language of both the organizers and participants are very important characteristics of the dance events, they all affect participants' mood and happiness so their involvement to the salsa events. Therefore, they recommended to event managers to bring salsa events into a visual entertainment. In order to take participants' attention and to trigger their senses, they may organize theme parties such as pajama parties, Christmas parties, cocktail or costume parties on the stage. Because participants would be more actively involved if they experienced something different engaging their senses.

Participants emphasized the emotional experience in the second order. Because they believe that salsa dancing is a wonderful way of expressing feelings. They claimed that they feel happy, relaxed, joyful, excited on the stage while they are dancing and it is the real experience. They further indicated that dancing is a way of letting off the steam; and it brings them in a good mood, thus it causes to strong feelings, emotions, interactions and loyalty to the salsa events.

As for changing attitudes and transforming them into behaviors, act experience, is the third important experiential quality. Participants indicated that the effects of salsa events on learning attitude are invaluable because of an active involvement and great opportunity for practicing. It was suggested that salsa events are really the great tool for reinforcing learning and providing challenge, because they believe that the more they practice the better they learn.

After changing attitudes with learning, participants indicated that they want to convert their lifestyle into active life with dancing. Therefore participants claimed that relational experience comes in the fourth place. They believe that dancing is a part of their identity and inevitably dancing is promoted as a way of life at salsa events. As for the managers, participants claimed that they are really successful on promoting dancing as a way of life but they should also arrange some other events to convert salsa dancing into lifestyle. In other words, they should organize salsa events which are able to add color to the participants' life.

Participants further indicated that creative thinking is another important experiential quality, but they emphasized that thinking experience must be on the fifth place after relational experience, 
Aky1ldz, M., Munusturlar, S. (2014). Examining experiential qualities on the stage: A study on leisure experience of Salsa dancing. International Journal of Human Sciences, 11(2), 625-635. doi: 10.14687/ijhs.v11i2.2999

because creative thinking happens if only they can't imagine life without dancing. If the stimuli provided by salsa events lead to think, it will be easy to think creatively. Participants were indicated that music is the most important stimuli for thinking creatively and upbeat music would certainly urge them to engage and inspire more. To establish the ground for creativity and to solve problems, participants also suggested event managers to create new ideas and new concepts for the salsa events.

In brief, in this study it was examined that experiential dimensions of the salsa events as a leisure activity. Hence, it can be said that dancing itself is an actually experiential leisure pursuit which provides all the experiential qualities; sense, emotional, think, act and relational experiences. The results of the study revealed that sense experience was the most important experiential dimension because of the music factor, it was also found that participants gave importance emotional, act, think and relational experiences, respectively during the salsa events.

\section{Limitations and Recommendations for Further Researches}

As for every research, this study is not free of some limitations and it suggests avenues for future research consideration. The respondents in the study were limited to those who live in a single Turkish city, Eskisehir. Consequently, the results may not adequately represent the total population in Turkey. Although the sample was appropriate for a survey on leisure experience, the results may differ if other people in different regions or leisure area are studied. In future studies, many cities providing leisure opportunities for dancing should be examined to compare participants' experiences in dancing.

Further researches may apply the conceptual framework to other types of dances, such as ballroom dances or hip-hop dance or jazz dance in which experience plays a crucial role for examining whether this consequence varies with the dancing styles difference. The next interesting area that should be investigated is the salsa dancing experience in different countries. Different countries have different cultural and social implications and different habits regarding salsa dancing as a leisure activity. Therefore, a future study that compares different samples of countries with different traditional dances can shed light on this issue.

The most peculiar limitation of this particular study emerges due to the nature of focus group studies. In other words, the focus group discussions have an inherent limitation that the individuals may not produce the most accurate picture of their thoughts and experiences about salsa dance events. However, findings of this study would certainly help developing quantitative research projects on this subject in future. Carrying out observational and quantitative studies may give more 
Akyldız, M., Munusturlar, S. (2014). Examining experiential qualities on the stage: A study on leisure experience of Salsa dancing. International Journal of Human Sciences, 11(2), 625-635. doi: 10.14687/ijhs.v11i2.2999

accurate inferences about the leisure experiences of the participants of the salsa events. Therefore, quantitative methods expand our results when it comes to matching our research questions.

\section{References}

Argan, M., Sever, N.S., \& Argan, M.T. (2009). Edutainment applications in marketing courses: Findings from focus group studies in Turkey. Business Research Yearbook, IABD's 21 th Annual Meeting, 2-4 April, St. Louis/Missouri, 16(2), 542-548.

Bond, K., \& Stinson, S. (2007). It's work, work, work, work: Young people's experiences of effort and engagement in dance. Research in Dance Education, 8(2), 155-183.

Borrie, W.T., \& Roggenbuck, J.W. (2001). The dynamic, emergent, and multi-phasic nature of onsite wilderness experiences. Journal of Leisure Research, 33(2), 202-228.

Clark, T., \& Holmes, S. (2007). Fit for practice? An exploration of the development of newly qualified nurses using focus groups. International Journal of Nursing Studies, 44, 1210-1220.

Cotte, J. S. (1998). Deciding what to do: A behavioral framework for leisure consumption decisions. PhD Thesis, University of Connecticut.

Crenan, M. (1993). Dance the movement activity for the elderly. Nursing Homes, $1^{\text {st }}$ of May, Retrieved from: Available from: http://www.allbusiness.com/health-care-socialassistance/nursing/375205-1.html.

Edmunds, H. (1999). The focus group research handbook. American Marketing Association, USA: McGraw Hill.

Gentile, C., Spiller, N., \& Noci, G. (2007). How to sustain the customer experience: An overview of experience components that co-create value with the customer. European Management Journal, 25(5), 395-410.

Hamilton, K., \& Hewer, P. (2009). Salsa magic: An exploratory netnographic analysis of the salsa experience. Advances in Consumer Research, 36, 502-508.

Kao, Y., Huang, L., \& Wu, C. (2008). Effects of theatrical elements on experiential quality and loyalty intentions for theme parks. Asia Pacific Journal of Tourism Research, 13(2), 163-174.

Krueger, R.A., \& Casey, M.A. (2000). Focus groups: A practical guide for applied research. $3^{\text {rd }}$ Edition, USA: Sage Publications.

Lagomarcino, A., Reid, D.H., Ivancic, M.T. \& Faw, G.D. (1984). Leisure-dance instruction for severely and profoundly retarded persons: Teaching and intermediate community-living skill. Journal of Applied Behavior Analysis, 17(1), 71-84.

Lee, B. (1999). The dynamic nature of emotions during a trail based leisure experiences: An application of affect control theory (ACT). PhD Thesis, Texas A\&M University.

Li, Y.C. (2008). A discussion of applying experiential marketing to leisure agriculture with AHP. The Journal of American Academy of Business, 13(1), 98-102.

Manfredo, M.J., Driver, B.L. \& Tarrant, M.A. (1996). Measuring leisure motivation: A meta-analysis of the recreation experience preference scales. Journal of Leisure Research, 28(3), 188-213.

Schmitt, B. (1999). Experiential marketing; how to get customers to sense, feel, think, act and relate to your company and brands. USA: Free Press.

Tsaur, S. H., Chiu, Y. T., \& Wang, C. H. (2006). The visitors behavioral consequences of experiential marketing; an empirical study on Taipei Zoo. Journal of Travel and Tourism Marketing, 21(1), 47-64.

Wearing, B., Wearing, S. \& Kelly, K. (1994). Adolescent woman identity and smoking: Leisure experience as resistance. Sociology of Health and Illness, 16(5), 626-643.

Zimmerer, E. (2005). Latin dance: Intermediate rumba, cha-cha and salsa. USA: Ace of Arts Publishing. 